\author{
V.A. Holovatsky ${ }^{1}$, M.V. Chubrei ${ }^{1}$, O.M. Yurchenko ${ }^{2}$
}

\title{
Impurity Photoionization Cross-Section and Intersubband Optical Absorption Coefficient in Multilayer Spherical Quantum Dots
}

\author{
${ }^{I}$ Yuriy Fedkovych Chernivtsi National University, Chernivtsi, Ukraine, v.holovatsky@chnu.edu.ua \\ ${ }^{2}$ Lesya Ukrainka Volyn National University, Lutsk, Ukraine, yurchenko.oksana@vnu.edu.ua
}

\begin{abstract}
Energy spectrum, wave functions and binding energies of the electron to the donor impurity ion located in the center of a multilayer spherical quantum dot (MSQD) consisting of a core (GaAs) and two spherical shells $\left(\mathrm{Al}_{\mathrm{x}} \mathrm{Ga}_{1-\mathrm{x}} \mathrm{As}\right.$ and $\left.\mathrm{GaAs}\right)$ were studied within the effective mass approximation. Based on the exact wave functions of the electron expressed in terms of Coulomb functions of the first and second kind, the spectral dependences of the photoionization cross section of the impurity (PCS) and the intersubband optical absorption coefficient (OAC) for various geometric dimensions of the nanostructure were calculated.

It is shown that the decrease in the width of the external potential well changes the localization of the electron in the nanosystem which significantly affects the binding energy of the electron with the impurity, photoionization cross section and interband absorption coefficient. The position of the PCS peak associated with the quantum transition of an electron from the ground state to the $1 \mathrm{p}^{0}$ state shifts to the region of higher energies, and its height decreases. At the same time, the height of PCS peaks associated with quantum transitions to higher excited states $\left(2 \mathrm{p}^{0}, 3 \mathrm{p}^{0}\right)$ increases.

The presence of impurities and changes in the MSQD size significantly affect the intersubband absorption coefficient. Decrease of the external potential well width in the absence of impurities leads to a monotonous increase in OAC through the first excited state, and in the presence of a central impurity, absorption through states with higher energy increases.

Obtained results enable prediction of the specifics of the effect of the magnetic field on the optical properties of MSQD with two potential wells.

Keywords: multilayer quantum dot, donor impurity, impurity photoionization cross section, impurity binding energy, optical absorption coefficient.
\end{abstract}

Received 25 August 2021; Accepted 05 October 2021.

\section{Introduction}

Multilayer spherical quantum dots (MSQD) which consist of a core and several shells of semiconductor materials with different bandgap values are intensively studied due to the prospects of their use in various nanoelectronics and nanophotonics devices. They can significantly improve existing and create fundamentally new semiconductor devices such as white light sources, high-efficiency photovoltaic devices, fluorescent labels with multimode radiation, various detectors, magnetooptical devices and memory elements for novel computers [1-5].
It is well known that the optical properties of semiconductor systems can be controlled by impurities, external electric and magnetic fields. The design of magneto- and electro-optical semiconductor devices necessitates theoretical studies of the optical properties of MSQD, the effect of impurities and external fields on their energy spectrum, localization of charge carriers in the complex confinement potential.

Most such studies are based on solutions of the oneparticle Schrödinger equation within the effective mass approximation. Finding the energies of several lowest states often employs different variational methods or the method of perturbation theory [6-16], the potential morphing method [17-19] or numerical finite element 
method [20-23]. Only for some problems one can find exact solutions of the Schrödinger equation, which are especially valuable because they can be used to calculate the full energy spectrum and to solve more complex problems. For example, the exact wave functions of an electron in an MSQD with rectangular potential wells and barriers are expressed by the linear combinations of the Bessel functions and form an orthonormal basis. The effect of charged impurities and external fields on the optical properties of MSQD was investigated by the matrix method using this basis [24-32]. In addition, the obtained expansion coefficients of the electron wave functions enable an estimate of the contribution of the states of the undisturbed system to the formation of new states of the quasiparticle.

The calculation of the energy spectrum and wave functions (WF) of an electron in spherical nanosystems with an impurity by the diagonalization method requires consideration of a large number of terms due to the presence of a singular potential. Diagonalization of such matrices encounters technical problems of solution stability.

For the case of a central impurity, this problem is solved by using exact solutions of the Schrödinger equation based on Mathieu and Whittaker functions, degenerate hypergeometric or Coulomb wave functions [33-37]. Their numerical calculation is more complicated than the Bessel functions, but using an orthonormal basis on Coulomb WFs decreases the size of the matrix required for diagonalization when studying the effect of electric or magnetic field on the impurity states in MSQD. Thus, such an orthonormal basis is a good and reliable tool for further theoretical research.

The authors of [38] used a similar orthonormal WF basis to study the effect of the magnetic field on the optical properties of spherical nanosystems of the core/shell type (MSQD with a single potential well). The use of exact solutions of the Schrödinger equation based on degenerate hypergeometric functions to study the binding energy of an electron and an impurity and the oscillator force of quantum transitions of quasiparticles in MSQD with two potential wells separated by potential barrier was demonstrated in [37, 39]. It was shown that the calculated binding energy agrees well with the results obtained by other methods, and that the dipole moment of quantum transitions depends significantly on the ratio of MSQD potential well width as this affects the distribution of the electron density in the nanosystem.

Studies of MSQDs with two and three wells [30, 40] show that a strong constant magnetic field reduces the effective width of the outer potential well which leads to changes in the electron localization in the ground and excited states and thus affects the dipole moment and the oscillator force of quantum transitions.

To increase the sensitivity of the optical properties of the nanosystem to the magnetic field, it is necessary to fit such MSQD core and shell size that the electron in the ground state is localized in the outer shell but transits into the inner shell upon a small decrease of the shell size [41]. Similarly, the MSQD size can be selected to increase the sensitivity of its optical characteristics to the electric field [29].

The impurity photoionization cross-section and the intersubband absorption coefficient are those optical characteristics that were intensely studied for simple spherical and cylindrical QDs and MSQDs with various profiles of confinement potential [10-14, 16-19, 32]. The effect of electric [32] and magnetic field [42] on the PCS of the central and off-center donor impurity in the spherical shell which forms a potential well of finite depth was investigated by the diagonalization method using an orthonormal basis of Bessel functions. The need to take into account quantum transitions to higher excited states was shown as their contribution increases with increasing external perturbation. Similar effects for MSQD with two wells were not studied although their sensitivity to external fields should be greater.

Here, we report the effect of the outer potential well width of the $\mathrm{GaAs} / \mathrm{Al}_{\mathrm{x}} \mathrm{Ga}_{1-\mathrm{x}} \mathrm{As} / \mathrm{GaAs} \mathrm{MSQD}$ with a central donor impurity on the energy spectrum, wave functions, binding energy, impurity photoionization cross-section and intersubband optical absorption coefficient.

\section{Theory}

The multilayer spherical quantum dot investigated in this work consists of a spherical core (GaAs) and two spherical shells $\left(\mathrm{Al}_{\mathrm{x}} \mathrm{Ga}_{1-\mathrm{x}} \mathrm{As}\right.$ and $\left.\mathrm{GaAs}\right)$ placed in a widegap medium. The MSQD core and the outer spherical shell form two potential wells for the electron, and the inner layer is a potential barrier which height $V$ is determined by its aluminium content $x$. The core radius is $r_{0}$, the thickness of the spherical layers are $\Delta_{l}$ and $\Delta_{2}$. The donor impurity is located in the center of the nanosystem core. The scheme of the potential energy of the electron in MSQD is shown in Fig. 1. The Schrödinger equation for the electron has the form:

$$
-\frac{\hbar^{2}}{2} \vec{\nabla} \frac{1}{\mu(r)} \vec{\nabla} \Psi_{n l m}(\vec{r})+\left[U(r)-\frac{Z e^{2}}{\varepsilon(r) r}\right] \Psi_{n l m}(\vec{r})=\mathrm{E}_{n l} \Psi_{n l m}(\vec{r}),
$$

where the coordinate dependences of the effective mass, dielectric constant and potential energy are expressed as:

$$
\mu(r)=m_{e}\left\{\begin{array}{ll}
m_{0}, & r \leq r_{0}, \quad r_{1}<r \leq r_{2}, \\
m_{1}, & r_{0}<r \leq r_{1}
\end{array} \quad \varepsilon(r)=\left\{\begin{array}{l}
\varepsilon_{0}, r_{0}<r \leq r_{1} \\
\varepsilon_{1}
\end{array}\right.\right.
$$




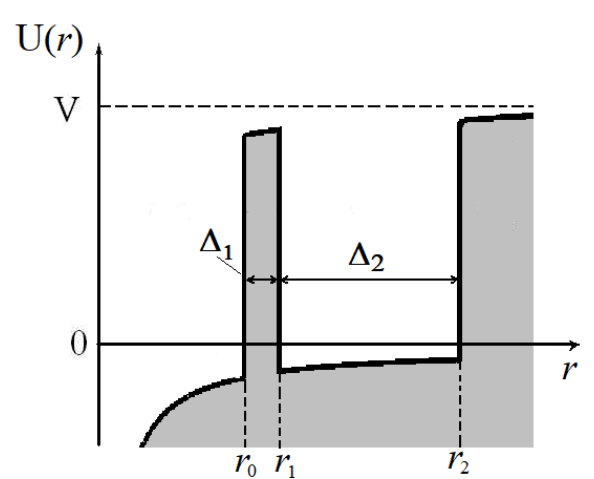

$$
U(r)= \begin{cases}0, & r \leq r_{0}, \quad r_{1}<r<r_{2}, \\ \mathrm{~V}, & r_{0}<r \leq r_{1}, \\ \infty, \quad r \geq r_{2},\end{cases}
$$

where $m_{\mathrm{e}}$ is the free electron mass.

Making Eq. (1) dimensionless by using the Rydberg energy $R y=m_{e} e^{4} / 2 \hbar^{2}$ as a unit of energy and the Bohr radius $a_{B}=\hbar^{2} / m_{e} e^{2}$ as a unit of length, and taking into account the spherical symmetry of problem, the equation for the radial part of the wave function is expressed as:

Fig. 1. Potential energy of the electron in $\mathrm{GaAs} / \mathrm{Al}_{\mathrm{x}} \mathrm{Ga}_{1-\mathrm{x}} \mathrm{As} / \mathrm{GaAs} \mathrm{MSQD}$ at $\mathrm{Z}=1$.

$$
\begin{aligned}
& -\frac{1}{m_{0}}\left[\frac{\partial^{2}}{\partial r^{2}}+\frac{2}{r} \frac{\partial}{\partial r}-\frac{\ell(\ell+1)}{r^{2}}\right] R_{n \ell}(r)-\frac{2 Z}{\varepsilon_{0} r} R_{n \ell}(r)=E_{n \ell} R_{n \ell}(r), \quad r \leq r_{0}, r_{1}<r \leq r_{2}, \\
& -\frac{1}{m_{1}}\left[\frac{\partial^{2}}{\partial r^{2}}+\frac{2}{r} \frac{\partial}{\partial r}-\frac{\ell(\ell+1)}{r^{2}}\right] R_{n \ell}(r)+\left(V-\frac{2 Z}{\varepsilon_{1} r}\right) R_{n \ell}(r)=E_{n \ell} R_{n \ell}(r), \quad r_{0}<r \leq r_{1}
\end{aligned}
$$

The general solutions of Eqs. (4) and (5) are expressed by a linear combination of degenerate hypergeometric functions of the first and second kind $F(\mathrm{a}, \mathrm{b}, \mathrm{z})$ and $G(\mathrm{a}, \mathrm{b}, \mathrm{z})$ :

$$
\begin{gathered}
R_{n \ell}(r)=\left\{\begin{array}{l}
A_{0} e^{-\xi_{0} r / 2} r^{\ell} F\left(\ell+1-\eta_{0}, 2 \ell+2, \xi_{0} r\right), \quad r \leq r_{0} \\
A_{1} e^{-\xi_{1} r / 2} r^{\ell}\left[F\left(\ell+1-\eta_{1}, 2 \ell+2, \xi_{1} r\right)+B_{1} G\left(\ell+1-\eta_{1}, 2 \ell+2, \xi_{1} r\right)\right], \quad \begin{array}{l}
r_{0}<r \leq r_{1}, \\
A_{2} e^{-\xi_{0} r / 2} r^{\ell}\left[F\left(\ell+1-\eta_{0}, 2 \ell+2, \xi_{0} r\right)+B_{2} G\left(\ell+1-\eta_{0}, 2 \ell+2, \xi_{0} r\right)\right], \\
r_{1}<r \leq r_{2},
\end{array} \\
\xi_{0}=-2 \operatorname{sign}\left(E_{n \ell}\right) \sqrt{m_{0}\left(-E_{n \ell}\right)}, \quad \eta_{0}=\frac{2 Z m_{0}}{\varepsilon_{0} \xi_{0}}, \xi_{1}^{e, h}=2 \operatorname{sign}\left(V-E_{n \ell}\right) \sqrt{m_{1}\left(V-E_{n \ell}\right)}, \eta_{1}=\frac{2 Z m_{1}}{\varepsilon_{1} \xi_{1}},
\end{array}\right.
\end{gathered}
$$

where $\operatorname{sign}(\mathrm{x})$ is a sign function that provides a single analytical form of WF for states with different signs of electron energy. The coefficients $\mathrm{A}_{0}, \mathrm{~A}_{1}, \mathrm{~A}_{2}, \mathrm{~B}_{1}, \mathrm{~B}_{2}$ and the energy spectrum of the electron are determined from the Ben-Daniel-Duke boundary conditions [39] and the normalization condition:

$$
\int_{0}^{r_{2}}\left|R_{n \ell}(r)\right|^{2} r^{2} d r=1
$$

Based on the energy spectrum and wave functions, the binding energy of the electron and the impurity in the state $(n l)$ and the effective photoionization cross-section are calculated by the formulas:

$$
E_{n l}^{b}=E_{n l}^{Z=0}-E_{n l}^{Z=1}
$$

$$
\sigma(\hbar \omega)=\frac{4 \pi^{2}}{3 n_{r}}\left(\frac{F_{e f f}}{F_{0}}\right)^{2} \beta_{F S} \hbar \omega \sum_{n}\left|\left\langle R_{n 1}^{Z=0}|r| R_{10}^{Z=1}\right\rangle\right|^{2} \delta\left(E_{b}-\hbar \omega\right),
$$

where $\delta\left(E_{b}-\hbar \omega\right)=\frac{\Gamma}{\pi\left\{\left[E_{b}-\hbar \omega\right]^{2}+\Gamma^{2}\right\}}, \quad \hbar \omega$ is the photon energy, $n_{r}$ is the refraction index, $\beta_{F S}=1 / 237$ is the fine structure constant, the ratio $F_{\text {eff }} / F_{0} \approx 1, \Gamma=0.4$ meV [32]. Eq. (10) takes into account that the polarization vector of the light wave coincides with the direction of the $\mathrm{OZ}$ axis, the integral over the angular variables gives the coefficient $1 / \sqrt{3}$, and the selection rule for intersubband quantum transitions for spherically symmetric systems is $\Delta \ell= \pm 1$. The sum over the 
quantum number $n$ takes into account the transitions to all possible $p$-states of the electron. The energy $E_{n l}^{Z=0}$ and wave functions $R_{n 1}^{Z=0}$ of the electron states in the absence of impurities can be calculated by two methods: by Eqs. (6), (7) for $Z=0$, or on the basis of the Bessel functions of the first and second kind [41].

Absorption coefficient was calculated for the cases of presence $(Z=1)$ and absence of impurities $(Z=0)$ according to the formula [27]:

$$
\alpha(\hbar \omega)=4 \pi \beta_{F S} \sum_{n} \frac{\left|\left\langle R_{n 1}|r| R_{10}\right\rangle\right|^{2} \rho \hbar \omega \hbar \Gamma_{0}}{\left(E_{n 1}-E_{10}-\hbar \omega\right)^{2}+\left(\hbar \Gamma_{0}\right)^{2}},
$$

where $\rho=1 / V$ is the carrier density in MSQD, $\Gamma_{0}=1 / \tau_{0}$, where $\tau_{0}=0.14 \mathrm{ps}$ is the relaxation time [27].

\section{Results and discussion}

The following physical parameters of $\mathrm{GaAs} / \mathrm{Al}_{\mathrm{x}} \mathrm{Ga}_{1-\mathrm{x}} \mathrm{As} / \mathrm{GaAs}$ MSQD were used in numerical calculations: $\mathrm{x}=0.3, m_{0}=0.067, m_{1}=0.067+0.083 \mathrm{x}$, $\varepsilon_{0}=13.18, \varepsilon_{1}=13.18-3.12 x[16], \mathrm{V}=0.6(1155 x+$ $\left.370 x^{2}\right) \mathrm{meV}, r_{0}=10 \mathrm{~nm}, r_{1}=12 \mathrm{~nm}, r_{2}=10-20 \mathrm{~nm}$.

The dependence of the energy spectrum of the electron in MSQD $\left(r_{0}=10 \mathrm{~nm}, \Delta_{1}=2 \mathrm{~nm}\right)$ on $\Delta_{2}$, the size of the outer potential well, is shown in Fig. 2. In the absence of impurities, at small values of $\Delta_{2}<r_{0}$ the electron is localized in the core of the nanosystem as shown by the horizontal region of the $E_{10}\left(\Delta_{2}\right)$ dependence, and at $\Delta_{2}>r_{0}$ the electron is located in the outer potential well where its energy is less. The change in the localization of the electron occurs in the region of energy levels $E_{10}$ and $E_{20}$ anticrossing $\left(\Delta_{2} \sim 10 \mathrm{~nm}\right)$. The width of the anticrossing region and its smoothness are determined by the width of the potential barrier $\Delta_{1}$. The $\mathrm{E}_{10}\left(\Delta_{2}\right)$ and $\mathrm{E}_{20}\left(\Delta_{2}\right)$ dependences in the anticrossing region at $\Delta_{1}=3 \mathrm{~nm}$ are shown in the insert to Fig. 1b. In the presence of a central donor impurity (Fig. 1a) the region of the anticrossing is shifted to $\Delta_{2} \sim 14 \mathrm{~nm}$ due to the Coulomb attraction.

The radial distribution of electron density $w(r)=\left|R_{n \ell}(r)\right|^{2} r^{2}$ in the ground and excited states that participate in quantum transitions and determine the optical properties of the nanosystem is presented in Fig. 3 . The dimensions of the outer potential well which

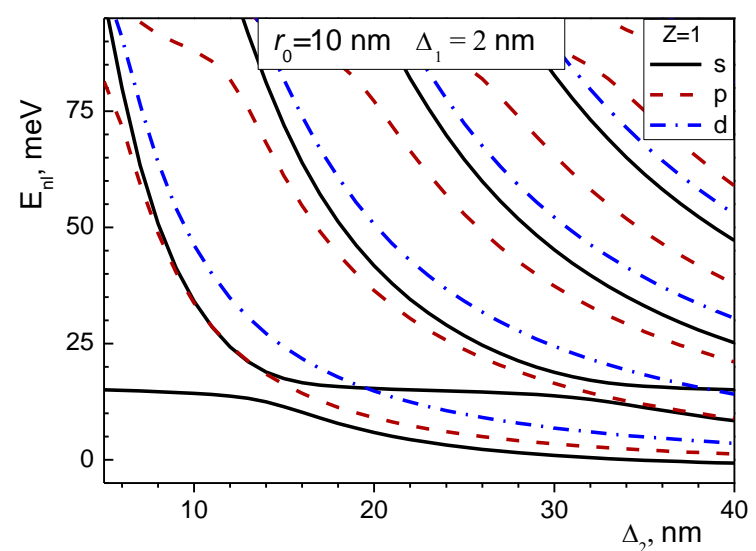

a)

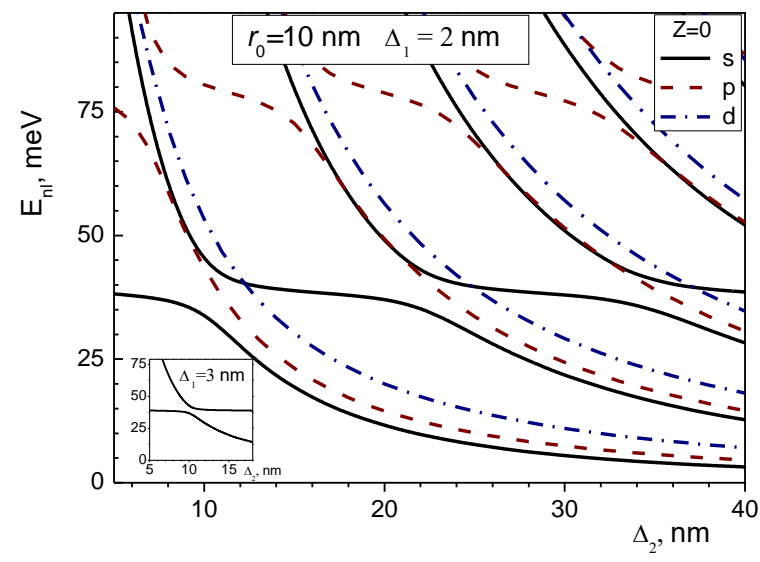

b)

Fig. 2. Dependence of the electron energy spectrum on $\Delta_{2}$ at $r_{0}=10 \mathrm{~nm}$ and $\Delta_{1}=2 \mathrm{~nm}(\mathrm{a}-\mathrm{Z}=1, \mathrm{~b}-\mathrm{Z}=0)$.

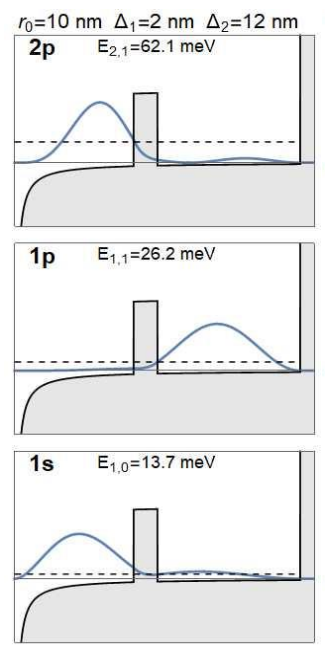

a)
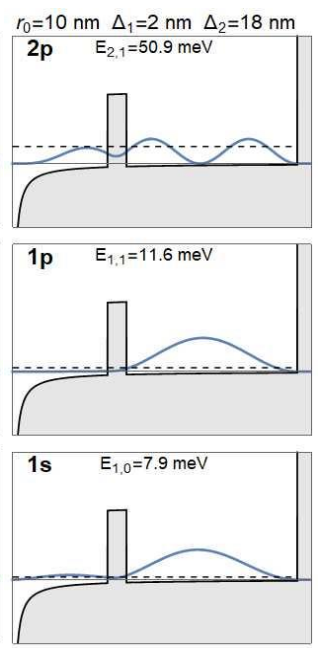

b)
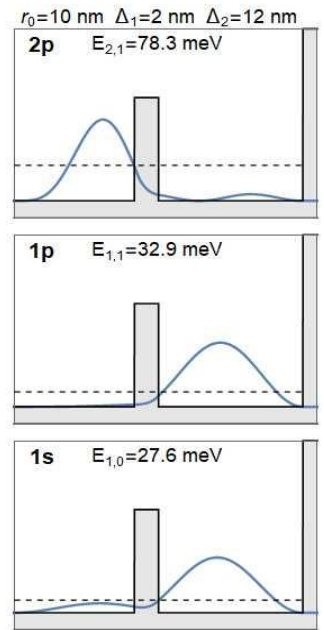

c)
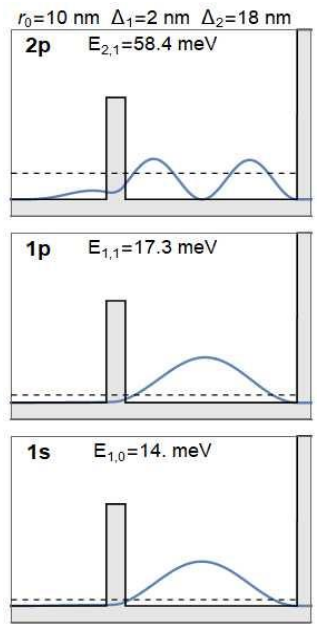

d)

Fig. 3. Distribution of electron density in $1 \mathrm{~s}, 1 \mathrm{p}, 2 \mathrm{p}$ states: $\mathrm{a}-\Delta_{2}=12 \mathrm{~nm}, \mathrm{Z}=1 ; \mathrm{b}-\Delta_{2}=18 \mathrm{~nm}, \mathrm{Z}=1 ; \mathrm{c}-\Delta_{2}=12$ $\mathrm{nm}, \mathrm{Z}=0 ; \mathrm{d}-\Delta_{2}=18 \mathrm{~nm}, \mathrm{Z}=0$. 


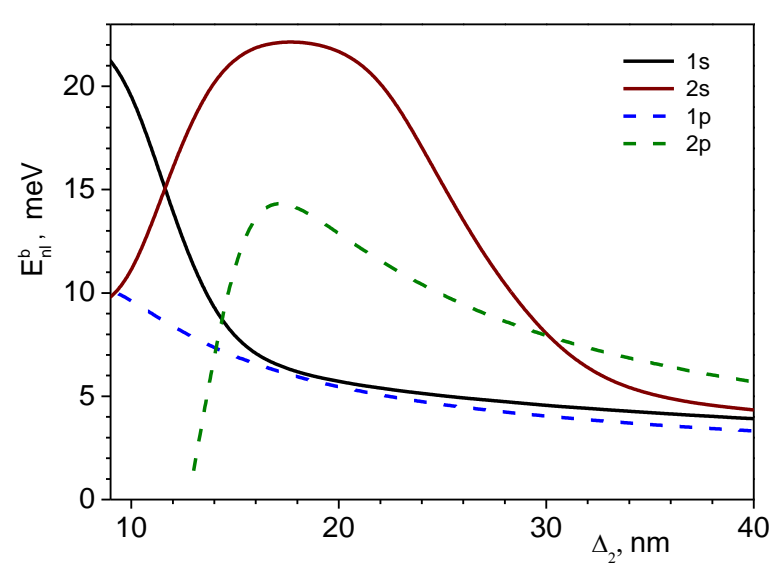

Fig. 4. Dependence of the binding energy $E_{n l}^{b}\left(\Delta_{2}\right)$ in the electron states $1 s, 2 s, 1 p, 2 p$.

correspond to the beginning $\left(\Delta_{2}=12 \mathrm{~nm}\right)$ and the end $\left(\Delta_{2}=18 \mathrm{~nm}\right)$ of the anticrossing region are selected for the display. This illustrates the peculiarities of the electron density redistribution in the anticrossing region.

A small perturbation can change the spatial distribution of electron density in the anticrossing region which should be reflected in various optical characteristics. Therefore, MSQD of such sizes is the most sensitive to influence of external fields.

Dependence of the binding energy of the electron to the impurity in $s$ and $p$ states are shown in Fig. 4. The maximum values of the binding energy of the electron to the impurity correspond to the case of localization of the electron in the core of the nanosystem. In the anticrossing regions of energy levels $E_{10}$ and $E_{20}$, as well as $E_{11}$ and $E_{21}$, the corresponding binding energy dependences are crossed. The binding energy in $p$ states is lower than that in $s$ states because of the shift of the electron density from nanosystem center due to the centrifugal term in the Hamiltonian.

The spectral dependence of impurity PCS for various values of $\Delta_{2}$ is plotted in Fig. 5. The main contributor to the PCS at $\Delta_{2}=20 \mathrm{~nm}$ is the quantum transition $1 \mathrm{~s}-1 \mathrm{p}^{0}$ which is confirmed by the overlap of the corresponding WFs (Fig. 3 b, d). At the same time, the magnitude of the dipole moment of the quantum transition $1 \mathrm{~s}-2 \mathrm{p}^{0}$ is much smaller than that of $1 \mathrm{~s}-1 \mathrm{p}^{0}$ due to the sign alternation of $2 \mathrm{p}^{0} \mathrm{WF}\left(R_{20}^{Z=0}\right)$. As the size of the outer potential well decreases, the electron in $1 \mathrm{~s}$ and $2 \mathrm{p}^{0}$ states is localized in the core. Therefore the first PCS peak $\left(1 \mathrm{~s}-1 \mathrm{p}^{0}\right)$ decreases and the second PCS peak associated with the $1 \mathrm{~s}-2 \mathrm{p}^{0}$ quantum transition increases. Additionally, upon decreasing $\Delta_{2}$ all PCS peaks are shifted to the region of higher energies.

Dependence of the light absorption coefficient on the photon energy for MSQD with impurity (solid lines) and without impurity (dashed lines) for various $\Delta_{2}$ values is shown in Fig. 6. Unlike PCS, the expression for OAC contains the dipole moment of the quantum transition between states at $\mathrm{Z}=1$ (in the presence of impurity) or at $\mathrm{Z}=0$ (in the absence of impurity). But the qualitative behavior of absorption peaks with decreasing $\Delta_{2}$ value is somewhat similar to PCS, i.e. a shift of peaks to the region of higher energies and an increase in the value of peaks of higher excited states. But in the absence of impurity, the first peak increases with the width of the outer potential well, whereas in the presence of impurity this absorption peak decreases and becomes smaller than the peak associated with the transition to the second excited state $2 p$.

Obtained changes in the spectral dependences $\sigma(\hbar \omega)$ and $\alpha(\hbar \omega)$ caused by the reduction of the outer potential well allow us to predict the effect of the external constant magnetic field on the MSQD optical characteristics. Increasing the induction of the magnetic field reduces the cyclotron radius of the electron

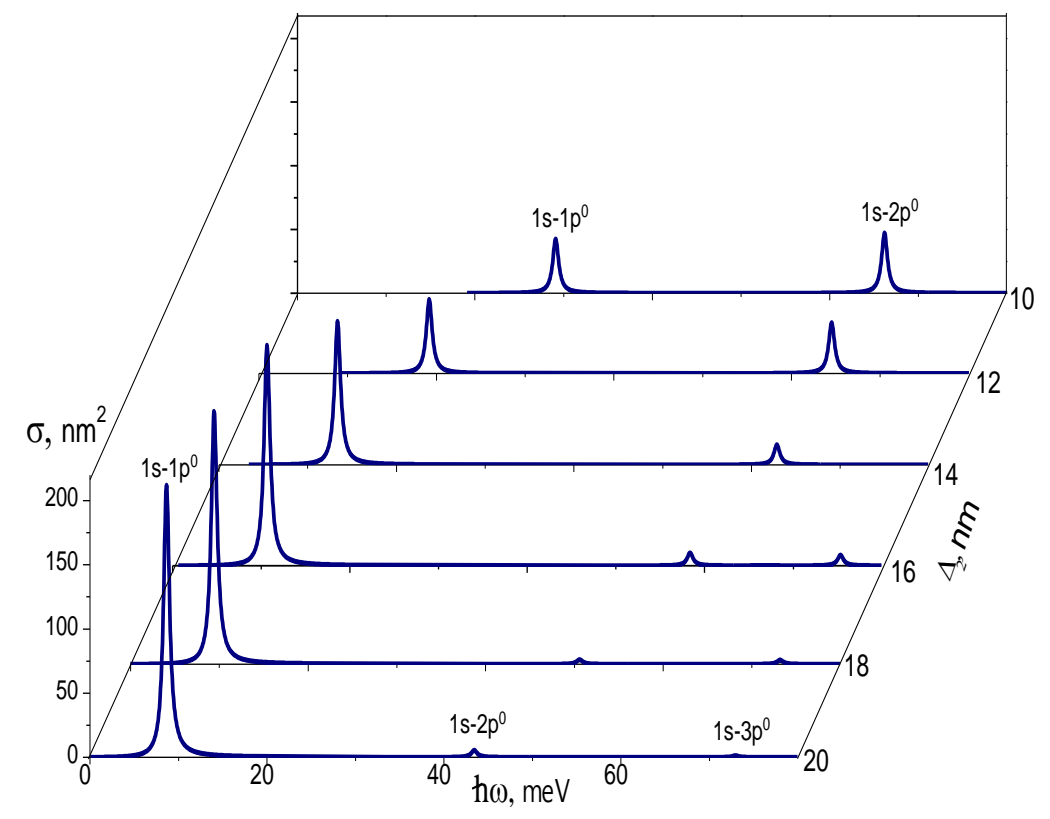

Fig. 5. Impurity PCS as function of photon energy for various $\Delta_{2}$ values. 


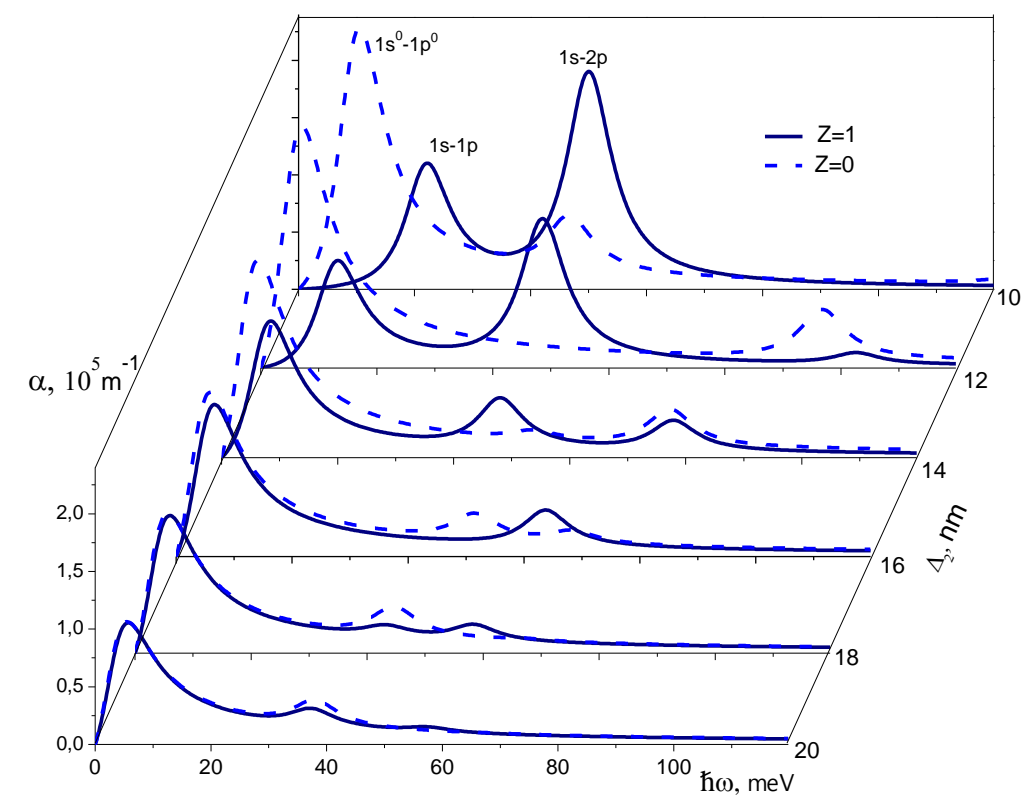

Fig. 6. Spectral dependence of the intersubband optical absorption coefficient of MSQD for various $\Delta_{2}$ values ( $\mathrm{Z}=1-$ solid lines, $\mathrm{Z}=0-$ dashed lines).

$r_{c}=\sqrt{2 \hbar / e B}$. If this becomes smaller than the MSQD radius, the magnetic field will increase the confinement and decrease the effective potential well width in the direction perpendicular to the magnetic field. The change of the electron localization under the selected MSQD dimensions will require $\sim 5-10 \mathrm{~T}$ induction of the magnetic field. The effect of the magnetic field on the optical properties of $\mathrm{GaAs} / \mathrm{Al}_{\mathrm{x}} \mathrm{Ga}_{1-\mathrm{x}} \mathrm{As} / \mathrm{GaAs} \mathrm{MSQD}$ with impurity will be investigated in the following study.

\section{Conclusions}

The exact solutions of the Schrödinger equation for the electron in a $\mathrm{GaAs} / \mathrm{Al}_{\mathrm{x}} \mathrm{Ga}_{1-\mathrm{x}} \mathrm{As} / \mathrm{GaAs} \mathrm{MSQD}$ with central impurity were obtained. The impurity photoionization cross-section and the intersubband absorption coefficient were investigated from the energy spectrum and wave function of the electron for various values of the size of the outer potential well. It was shown that in the region of anticrossing of the energy levels the nanosystem is most sensitive to the effect of impurity and external fields on its optical characteristics. A decrease of the size of the outer potential well of
MSQD leads to the shift of PCS and OAC peaks to the high-energy region and to an increase in the contribution of quantum transitions to higher excited states to the optical characteristics. Absent of impurity in MSQD, intersubband absorption occurs mainly through the quantum transition $1 \mathrm{~s}^{0}-1 \mathrm{p}^{0}$, whereas in the presence of a central impurity the greatest absorption occurs at higher photon energy through the quantum transition $1 \mathrm{~s}-2 \mathrm{p}$. Obtained research results enable predictions of the effect of a strong magnetic field on the optical properties of MSQD.

Holovatsky V. - Professor, Ph.D., Professor of the Department of Theoretical Physics and Computer Modelling

Chubrei M. - postgraduate student of the Department of Theoretical Physics and Computer Modelling

Yurchenko O. - Associate Professor, Ph.D., Associate Professor of the Department of Chemistry and Technologies

[1] Z. Zhang, Chem. Mater 27, 1405 (2015); https://doi.org/10.1021/cm5047269.

[2] G.Yu. Rudko, V.I. Fediv, I. Davydenko, E.G. Gule, O. Olar, A.O. Kovalchuk, Nanoscale Research Letters 11, 83 (2016); https://doi.org/10.1186/s11671-016-1300-5.

[3] K. Chatterjee, S. Sarkar, R. K. Jagajjanani, S. Paria, Adv Colloid Interf Sci. 209(7), 8 (2014); https://doi.org/10.1016/j.cis.2013.12.008.

[4] S. Lahon, P. K. Jha, M. Mohan, Journal of Applied Physics 109, 5 (2011); https://doi.org/10.1063/1.3559271.

[5] S. Jiao, Q. Shen, I. Mora-Seró, J. Wang, Z. Pan, K. Zhao, Y. Kuga, X. Zhong, J. Bisquert, ACS Nano 9(1), 908 (2015); https://doi.org/10.1021/nn506638n. 
[6] J.-H. Yuan, W.-F. Xie, L.-L. He, Commun. Theor. Phys. 52(4), 710 (2009); https://doi.org/10.1088/02536102/52/4/306102/52/4/30.

[7] W. Xie, Physica B 405(16), 3436 (2010); https://doi.org/10.1016/j.physb.2010.05.019.

[8] E. Sadeghi, Superlattice Microstructures 50(4), 331 (2011); https://doi.org/10.1016/j.spmi.2011.07.011.

[9] C. Dane, H. Akbas, A. Guleroglu, S. Minez, and K. Kasapoglu, Physica E 44(1), 186 (2011); https://doi.org/10.1016/j.physe.2011.08.012.

[10] L.M. Burileanu, J. Luminescence 145, 684 (2014); https://doi.org/10.1016/j.jlumin.2013.08.043).

[11] Corella Madueno, R. Rosas, J.L. Marın, R. Riera, J. Appl. Phys. 90(5), 2333 (2001); https://doi.org/10.1063/1.1329143.

[12] E. Feddi, A. Talbi, M.E. Mora-Ramos, M.El. Haouari, F. Dujardin, and C.A. Duque, Physica B 524(11), 64 (2017); https://doi.org/10.1016/j.physb.2017.08.057.

[13] M.G. Barseghyan, A.A. Kirakosyan, and C.A. Duque, Eur. Phys. J. B 72(11), 521 (2009); https://doi.org/10.1140/epjb/e2009-00391-0.

[14] S. Li, L. Shi, and Z.-W. Yan, Mod. Phys. Lett. B 34, 2050153 (2020); https://doi.org/10.1142/s0217984920501535.

[15] V.A.Holovatsky, I.B. Frankiv, Journal of Optoelectronics and Advanced Materials 15(1-2), 88 (2013).

[16] F.K. Boz, S. Aktas, A. Bilekkaya, S.E. Okan, Applied Surface Science 256(12), 3832 (2010); https://doi.org/10.1016/j.apsusc.2010.01.036.

[17] I. Karabulut, S. Baskoutas, Journal of Applied Physics 103(7), 1 (2008); https://doi.org/10.1063/1.2904860.

[18] Z. Zeng, C.S. Garoufalis, S. Baskoutas, A.F. Terzis, Physics Letters, Section A: General, Atomic and Solid State Physics 376 (42-43), 2712 (2012); https://doi.org/10.1016/j.physleta.2012.07.032.

[19] Z. Zeng, C.S. Garoufalis, A.F. Terzis, S. Baskoutas, Journal of Applied Physics 114(2), 023510 (2013); https://doi.org/10.1063/1.4813094.

[20] M. Cristea, E.C. Niculescua, European Phys. J. B, 85(6), 191 (2012); https://doi.org/10.1140/epjb/e201221051-2.

[21] E.C. Niculescu, C. Stan, M. Cristea, C. Truscă, Chemical Physics, 493, 32 (2017); https://doi.org/10.1016/j.chemphys.2017.06.004.

[22] M. Cristea, Physica E: Low-Dimensional Systems and Nanostructures 103, 300 (2018); https://doi.org/10.1016/j.physe.2018.06.019.

[23] C.Heyn, C.A. Duque, Scientific Reports 10(1), 1 (2020); https://doi.org/10.1038/s41598-020-65862-9.

[24] B. Çakir, U. Atav, Y. Yakar, A. Özmen, Chem. Phys. 475, 61 (2016); https://doi.org/10.1016/j.chemphys.2016.06.010.

[25] D.-M. Liu, W.-F. Xie, Commun. Theor. Phys. 51(5), 919 (2009); https://doi.org/10.1088/0253-6102/51/5/32.

[26] E.B. Al, E. Kasapoglu, S. Sakiroglu, H. Sari, I. Sökmen, and C.A. Duque, Physica E 119, 114011 (2020); https://doi.org/10.1016/j.physe.2020.114011.

[27] E.B. Al, E. Kasapoglu, H. Sari, I. Sökmen, Physica B: Condensed Matter 613, 412874 (2021); https://doi.org/10.1016/j.physb.2021.412874.

[28] V.I. Boichuk, I.V. Bilynskyi, R.Y. Leshko, and L.M. Turyanska, Physica E 44(2), 476 (2011); https://doi.org/10.1016/j.physe.2011.09.025.

[29] V.A. Holovatsky, M.Y. Yakhnevych, and O.M. Voitsekhivska, Condens. Matter Phys. 21, 13703 (2018); https://doi.org/10.5488/CMP.21.13703.

[30] V.A. Holovatsky, I.B. Bernik, and M.Y. Yakhnevych, Physica B 508, 112 (2017); https://doi.org/10.1016/j.physb.2016.12.024.

[31] V.A. Holovatsky, O.M. Voitsekhivska, and M.Y. Yakhnevych, Superlattices and Microstructures 116, 9 (2018); https://doi.org/10.1016/j.spmi.2018.02.006.

[32] V. Holovatsky, M. Chubrey, and O. Voitsekhivska, Superlattices and Microstructures 145, 106642 (2020); https://doi.org/10.1016/j.spmi.2018.02.006.

[33] A.S. Baimuratov, I.D. Rukhlenko, V.K. Turkov, I.O. Ponomareva, M.Y. Leonov, T.S. Perova, K. Berwick, A.V. Baranov, A.V. Fedorov, Scientific Reports, 4, 1 (2014); https://doi.org/10.1038/srep06917.

[34] V.I. Boichuk, I.V. Bilynskyi, R.Y. Leshko, Condensed Matter Physics 13(1), 13702 (2010); https://doi.org/https://doi.org/10.5488/CMP.13.13702.

[35] Y. Naimi, A.R. Jafari, Journal of Computational Electronics 11(4), $414 \quad$ (2012); https://doi.org/https://doi.org/10.1007/s10825-012-0421-z.

[36] R. Kostić, D. Stojanović, Journal of Nanophotonics 6(1), $061606 \quad$ (2012); https://doi.org/https://doi.org/10.1117/1.jnp.6.061606.

[37] I.F.I. Mikhail, S.B.A. El Sayed, Physica E: Low-Dimensional Systems and Nanostructures 43(7), 1371 (2011); https://doi.org/10.1016/j.physe.2011.03.007.

[38] F. Rahimi, T. Ghaffary, Y. Naimi, H. Khajehazad, Optical and Quantum Electronics 53, 47 (2021); https://doi.org/10.1007/s11082-020-02695-w.

[39] V. Holovatsky, I. Bernik, O. Voitsekhivska, Acta Phys. Pol. A, 125, 1 (2014); https://doi.org/10.12693/APhysPolA.125.93.

[40] V.A. Holovatsky, O.M. Voitsekhivska, M.Y. Yakhnevych, Physica E: Low-Dimensional Systems and Nanostructures 93, 295 (2017); https://doi.org/10.1016/j.physe.2017.06.019. 
Impurity Photoionization Cross-Section and Intersubband Optical Absorption Coefficient...

[41] V. Holovatsky, I. Bernik, M. Yakhnevych, Physica E: Low-Dimensional Systems and Nanostructures, 83 (2016); https://doi.org/10.1016/j.physe.2016.04.035.

[42] M.V. Chubrey, V.A. Holovatsky, C.A. Duque, Philosophical Magazine, (in press) (2021); https://doi.org/10.1080/14786435.2021.1979267.

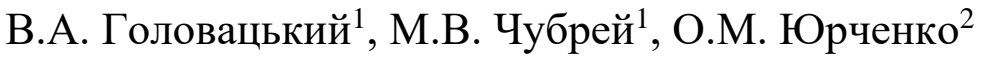

\title{
Переріз фотоіонізації домішки та коефіцієнт міжпідзонного поглинання світла в багатошарових сферичних квантових точоках
}

\footnotetext{
${ }^{1}$ Чернівецький національний університет імені Юрія Федьковича, Чернівиі, Україна, v.holovatsky@chnu.edu.ua ${ }^{2}$ Волинський національний університет імені Лесі Украӥнки, Луцьк, Украӥна, yurchenko.oksana@vпи.еdи.иа

У рамках наближення ефективної маси досліджено енергетичний спектр, хвильові функції та енергії зв'язку електрона з іоном донорної домішки, розміщеним в центрі багатошарової сферичної квантової точки (БСКТ), що складається з ядра (GaAs) та двох сферичних оболонок ( $\mathrm{Al}_{\mathrm{x}} \mathrm{Ga}_{1-\mathrm{x}} \mathrm{As}$ та $\left.\mathrm{GaAs}\right)$. На основі точних хвильових функцій електрона, які виражаються через кулонівські функції першого та другого роду, розраховано спектральні залежності перерізу фотоіонізації домішки (ПФД) та коефіцієнта міжпідзонного поглинання (КМП) за різних геометричних розмірів наноструктури.

Показано, що внаслідок зменшення ширини зовнішньої потенціальної ями змінюється локалізація електрона в наносистемі, що суттєво впливає на енергію зв'язку електрона 3 домішкою, переріз фотоіонізації та коефіцієнт міжпідзонного поглинання. Положення піка ПФД, пов'язаного з квантовим переходом електрона 3 основного стану в стан $1 p^{0}$, зміщується в область вищих енергій і зменшується його висота. Водночас зростає висота піків ПФД, що пов'язані з квантовими переходами у більш збуджені стани $\left(2 \mathrm{p}^{0}, 3 \mathrm{p}^{0}\right)$.

Наявність домішки та зміна розмірів БСКТ суттєво впливає на коефіцієнт міжпідзонного поглинання. Зменшення ширини зовнішньої потенціальної ями БСКТ у відсутності домішки приводить до монотонного збільшення КМП через перший збуджений стан, а у випадку наявності центральної домішки зростає поглинання через стани з більшими енергіями.

Отримані результати дають можливість передбачити особливості впливу магнітного поля на оптичні властивості БСКТ з двома потенціальними ямами.

Ключові слова: багатошарова квантова точка, донорна домішка, переріз фотоіонізації домішки, енергія зв'язку домішки, оптичний коефіцієнт поглинання.
} 